Title:

\title{
Change and onset-type differences in the prevalence of comorbidities in people with multiple sclerosis
}

Authors:

Lara Marie Pangan Lo ${ }^{1}$, Bruce V. Taylor ${ }^{1}$, Tania Winzenberg ${ }^{1}$, Andrew J. Palmer ${ }^{1,2}$, Leigh Blizzard $^{1}$, Ingrid van der $\mathrm{Mei}^{1{ }^{1, *}}$

\section{Affiliation:}

${ }^{1}$ Menzies Institute for Medical Research, University of Tasmania, Hobart, TAS 7000, Australia

${ }^{2}$ Centre for Health Policy School of Population and Global Health, The University of Melbourne, Level 4, 207 Bouverie Street, Melbourne, VIC, 3053, Australia

\section{*Corresponding Author:}

A/Prof Ingrid van der Mei

Menzies Institute for Medical Research, University of Tasmania,

17 Liverpool Street, Hobart, TAS 7000, Australia.

Phone: (61) 362267710 and Fax: (61) 362267704

Email: Ingrid.vanderMei@utas.edu.au

\section{Keywords:}

multiple sclerosis, comorbidity, prevalence, prevalence ratio, MS onset-type 
Changes in prevalence of comorbidities in people with MS

\begin{abstract}
Background: Little is known about the change in prevalence of comorbidities during the disease course of people with multiple sclerosis (MS) and whether the prevalences vary by MS onset-type.
\end{abstract}

Objective: To calculate the change in prevalence of comorbidities between symptom onset and the time of study, to compare the prevalences of comorbidities with those in the Australian population at the time of study and to examine onset-type differences.

Methods: Comorbidity data from 1,518 participants of the Australian MS Longitudinal Study and Australian population comparator data (2014-15 National Health Survey) were used. The change in prevalence between time points and prevalence ratios (PR) at the time of study (crude, age-and-sex adjusted, and stratified by onset-type) were calculated.

Results: Comorbidities were common, and those with the largest increases in prevalence between MS symptom onset and the time of study were depression $(+26.9 \%)$, anxiety $(+23.1 \%)$, hypertension $(+21.9 \%)$, elevated cholesterol $(+16.3 \%)$, osteoarthritis $(+17.1 \%)$, eye diseases $(+11.6 \%)$, osteoporosis $(+10.9 \%)$ and cancer $(+10.3 \%)$. Compared to the general population and after age-and-sex adjustment, participants had a significantly higher prevalence for 14/19 comorbidities at the time of study. The associations were strongest for anaemia, cancer (both $\mathrm{PR}>4.00$ ), anxiety, depression, migraine (all $\mathrm{PR}>3.00$ ), psoriasis and epilepsy (both $\mathrm{PR}>2.00$ ). No significant differences were seen by onset-type.

Conclusion: Comorbidities are common at MS symptom onset and increase with MS duration. Having MS may thus contribute to accrual of comorbidities. This emphasises the importance of optimal screening for and management of comorbidities in early MS and throughout the disease course. 
Changes in prevalence of comorbidities in people with MS

\section{Introduction}

As there is still no known cure for multiple sclerosis (MS), current treatment mainly focuses on preventing relapses and disability progression as well as improving other health outcomes of people with MS (PwMS) [1]. However, MS-related outcomes are highly heterogeneous [2,3]. Comorbidities, the medical conditions that co-occur with an index disease [4], may explain part of the heterogeneity of clinical outcomes in MS. Comorbidities have recently engendered substantial research interest in MS because their presence can cause diagnostic delays, alter disability progression, limit physical activities [5], increase MS symptoms severity [6], lower quality of life [7], and affect MS treatment utilization and mortality [8].

Comorbidities are common in chronic diseases like MS and their accumulation over time complicates disease management. However, no study has focused on identifying comorbidities with increases in prevalence after MS symptom onset. Most studie-009is have examined the prevalence of comorbidities of PwMS cross-sectionally during the course of MS, generally finding a higher prevalence in PwMS of most diseases compared to controls [9-12]. Other studies focused on the time before and at MS onset, finding that the prevalence of hypertension, inflammatory bowel disease (IBD), high cholesterol [13], asthma [14], anaemia, thyroid disorders, epilepsy, migraine, any mood or anxiety disorders and depression $[15,13]$ were already more common before or at MS symptom onset compared to controls. In one study, comorbidities were already common five years before MS onset and became more prevalent at the time of symptom onset [16]. Two longitudinal studies found that after MS diagnosis, PwMS were at greater risk of cardiovascular diseases compared to healthy controls [17,18]. A good understanding of how the prevalence of comorbidities changes at these critical time points and which comorbidities are more common is important to better improve health outcomes. 
Changes in prevalence of comorbidities in people with MS

Furthermore, the last two decades showed dramatic progress for people with relapsing remitting MS in terms of risk factors and therapies [19,20]. For all the success in relapsing remitting MS, the story in progressive MS is more challenging. Previous research comparing the differences in characteristics and epidemiological features between relapse-onset and progressive-onset MS is limited and no study has yet compared the different effects on the prevalence of comorbidities between these two onset-types.

The aims of our study were to: (a) determine the change in prevalence of comorbidities between MS symptom onset and at the time of study (on average 20.5 years post-symptom onset) among the Australian MS Longitudinal Study (AMSLS) participants; (b) compare the prevalence of comorbidities at the time of study to the general Australian population, and; (c) examine whether the results differed by MS onset-type.

\section{Methodology}

\section{Study populations}

The study sample was recruited from the AMSLS database, a large, national sample of around 3,000 adult Australian volunteers with MS [21]. An estimated $96 \%$ of the participants were diagnosed by a neurologist with definite MS using the McDonald Criteria [22,23]. It is an ongoing survey-based research project supported by MS societies in all Australian states and territories. Ethical approval was initially given by the Australian Capital Territory Health Human Research Ethics Committee (HREC) and by the Tasmanian Health and Medical HREC when the study centre was relocated to Tasmania in 2014 [21]. Written informed consent forms for the survey were provided by each participant. In August to October 2016, a total of 
Changes in prevalence of comorbidities in people with MS

3,112 active participants were invited to complete the AMSLS Lifestyle and Environment Survey of whom 1,518 (49\%; 1,067 online and 451 paper-based) responded to the survey.

As a direct comparator, we used the 2014-15 National Health Survey (2014-15 NHS) conducted by the Australian Bureau of Statistics from July 2014 to June 2015 [24]. Detailed information about the 2014-15 NHS design, methodology and interpretation of results has been published [24]. In brief, a total sample of 19,259 (82\% response rate) Australians were randomly selected from all states and territories to assess their health status and health-related aspects of their lifestyles [24]. Estimates from the survey were obtained using a complex weighting and estimation procedure to ensure that results from sample survey infer results for the in-scope total population by state, age and sex [11,24]. Data on major long-term health conditions (number of people with the medical condition and total number of respondents) were extracted in 10-year age groups $(<35,35-44,45-54,55-64,65-74$ and 75 years and over) and stratified by sex.

\section{Measurements}

\section{Comorbidities}

Participants were asked about the presence of 30 comorbidities that have been previously frequently reported in prior comorbidity studies in MS $[9,25,26]$. For each comorbidity, we asked "Do you have or have you had this condition?" (Yes/No). If yes, the participant was coded as having that comorbidity at the time of study and we asked, "Did you have this before your first symptom of MS? " (yes/no/don't know). If yes, the participant was coded as having the comorbidity at MS symptom onset. The "Don't know" group was combined with the "No" group. The number of comorbidities for the total cohort, for those with relapse-onset and progressive-onset MS at these two time points were calculated. To make appropriate comparisons with the comorbidities reported in the 2014-15 NHS, we: 1) excluded comorbidities that were not included in the 2014-15 NHS (other autoimmune disorders, 
Changes in prevalence of comorbidities in people with MS

Parkinson's disease, systemic lupus erythematosus) or not assessed in a similar fashion in both surveys (eye diseases, allergies); 2) re-grouped or combined some comorbidities to match the 2014-15 NHS disease categories (as described in Figure 1 footnotes) and 3) excluded comorbidities that had $<10$ participants (chronic renal disease) in order to have sufficient power for the analysis. We were left with 19 comorbidities for the prevalence ratio analysis (Figure $1)$.

\section{$\underline{\text { Other measures }}$}

MS duration was calculated by subtracting the year of MS symptom onset from the year of survey. Age at symptom onset was calculated by subtracting the year of MS symptom onset from the year of birth. Data on age, sex, MS onset-type (i.e. relapse-onset and progressiveonset), disease modifying therapy (DMT) status and education attainment were also obtained from the survey.

\section{Statistical analysis}

We used descriptive statistics to examine the demographics of the MS cohort and the 2014-15 NHS. The characteristics of the study sample were compared to the participants who were invited but not included in the study to ascertain the generalisability across the sample. We calculated the crude prevalence of each comorbidity at MS symptom onset and at the time of completing the 2016 Lifestyle and Environment Survey (i.e. at the time of study) and calculated the change between those two time points.

To compare the prevalence of comorbidities between our MS cohort and the general Australian population, we calculated the crude prevalence of the 19 comorbidities in the MS cohort at the time of study and the crude prevalence of that comorbidity in the general Australian population. This process was repeated for each sex and age category. Using this dataset of rates for each 
Changes in prevalence of comorbidities in people with MS

sex and age category in the two cohorts, we used Poisson regression to adjust the prevalence ratio (PR) for sex and age at the time of study.

We then stratified the comorbidity data by MS onset-type (i.e. relapse-onset vs progressiveonset) and calculated the crude prevalence of each comorbidity at MS symptom onset and at the time of study. To compare the prevalence of comorbidities between people with relapseonset MS and people with progressive-onset MS, we calculated the crude prevalence of each comorbidity in the relapse-onset cohort at both time points and the crude prevalence of that comorbidity in the progressive-onset cohort. After obtaining a dataset of rates for each sex and age category in the two cohorts, we used Poisson regression to adjust the prevalence ratio (PR) for age and sex between both time points, respectively. To further examine whether the PR of both MS onset-types differed from the general Australian population at the time of study, we repeated the analysis above and calculated the p-values of interaction by including product terms in our model.

We limited all PR analyses to those comorbidities that had 10 or more participants to have sufficient power. All analyses were performed using STATA/IC for Windows (version 15.0; StataCorp LP, College Station, Texas, USA). The significance level was set at 95\% confidence interval (CI).

\section{Results}

\section{Participant characteristics}

Of the MS cohort, $79.6 \%$ were female (vs $50.8 \%$ of the $2014-15$ NHS participants), $88.1 \%$ had relapse-onset MS and 62.4\% were currently taking disease modifying therapy (Table 1). The mean age of all included participants at symptom onset was 36.0 years while the mean age at the time of study was 55.7 years. Almost $37 \%$ of the MS cohort had bachelor's and 
Changes in prevalence of comorbidities in people with MS

postgraduate degree (vs $28 \%$ of the 2014-15 NHS participants). Overall, $65.3 \%$ of the participants reported at least one comorbidity at symptom onset and $90.0 \%$ at the time of study.

The participants included in this analysis had a similar sex distribution (female $79.5 \%$ vs $77.2 \% ; p=0.10)$ and education attainment ( $37 \%$ with bachelor's or postgraduate degree vs $34 \%$; $p=0.11$ ) compared to participants who were not included. Included participants were slightly older $(+1.49$ years, $p<0.01)$ and had a longer MS duration since MS diagnosis $(+0.56$ years, $p=0.04)$.

\section{Prevalence of comorbidities at MS symptom onset vs at the time of the study}

Table 2 gives the prevalence of all thirty comorbidities assessed. At symptom onset, the most prevalent comorbidities were allergies (29.2\%), migraine (20.2\%), anxiety (15.9\%), depression (15.8\%), hypertension (8.3\%), high cholesterol (7.2\%) and anaemia (7.2\%) (Table 2). At the time of study (on average 20.5 years post-symptom onset), the most prevalent comorbidities were depression (42.7\%), anxiety (39.0\%), allergies (37.4\%), hypertension (30.2\%), migraine (28.1\%), high cholesterol $(23.5 \%)$ and osteoarthritis $(23.3 \%)$. The comorbidities with the highest change in prevalence from symptom onset to the time of study were depression $(+26.9 \%)$, anxiety $(+23.1 \%)$, hypertension $(+21.9 \%)$, osteoarthritis $(+17.1 \%)$, high cholesterol $(+16.3 \%)$, eye diseases $(+11.6 \%)$, osteoporosis $(+10.9 \%)$ and cancer $(+10.3 \%)$.

\section{Prevalence ratios of comorbidities at the time of the study}

Compared to the general Australian population and after age-and-sex adjustment, PwMS had a significantly higher prevalence of most comorbidities (14/19) at the time of study (Figure 1). The associations were strongest for anaemia, cancer (both $\mathrm{PR}>4.00$ ), anxiety, depression, migraine (all PR>3.00), psoriasis and epilepsy (both $\mathrm{PR}>2.00$ ). The participants were less likely to have type 1 diabetes compared to the general Australian population $(\mathrm{PR}=0.63)$.

\section{Prevalence and Prevalence ratios by MS onset-type}


Changes in prevalence of comorbidities in people with MS

Compared to progressive-onset MS and after age and sex adjustment, the prevalence of comorbidities in people with relapse-onset MS were not significantly different at MS symptom onset (Table 3). At the time of study and after age adjustment, people with relapse-onset MS were significantly more likely to have allergies compared with progressive-onset MS. There were no other statistically significant associations. Similarly, compared to the general Australian population and after age-and-sex adjustment, the participants had no significant differences in prevalence ratios of comorbidities when stratified by MS onset-type at the time of study (Table 4).

\section{Discussion}

The present study comprehensively examined the changes in the prevalence of a wide range of comorbidities between symptom onset and at the time of study using a large sample of Australians with MS and determined the effects of MS onset-types on the prevalence of their comorbidities. In this MS cohort, comorbidities were already prevalent at MS symptom onset, but the prevalence was substantially higher a mean of 20.5 years after symptom onset. At this time, 14 out of 19 comorbidities were significantly more common in PwMS compared to the general population. Having MS may contribute to the risk of accrual of comorbidities or there

may be shared pathogeneses and/or risk factors between MS and other diseases. Regardless of the reason, these findings suggest that early identification of comorbidities and minimising the development of new comorbidities throughout the disease process is an important consideration in the management of people with MS. The lack of significant differences by MS onset-type suggests that the management and screening for comorbidities is equally important in both onset-types. 
Changes in prevalence of comorbidities in people with MS

Mental health and physical comorbidities were already prevalent at the time of onset $(65.3 \%$ with $\geq 1$ comorbidity), with the most common comorbidities being allergies $(29.2 \%)$, migraine (20.2\%), anxiety (15.9\%), depression (15.8\%), hypertension $(8.3 \%)$, high cholesterol $(7.2 \%)$ and anaemia (7.2\%). A high prevalence of comorbidities is consistent with previous literature $[27,13]$, and is associated with a longer time to diagnosis, higher disability level at MS diagnosis and faster disability progression over time [3]. It is therefore important that clinicians are aware of the presence of any of these comorbidities at the diagnosis of a first demyelinating event and treat the patient holistically with these comorbidities in mind. They may also consider screening for (additional) comorbidities or the risk factors of comorbidities as soon as practical. Useful documents to guide clinicians on screening and management practices include the National Institute for Health and Care Excellence (NICE) guidelines on multimorbidity [28] and a Clinical Resource Guide on comorbidities in Multiple Sclerosis [29].

At a mean of 20.5 years post-symptom onset, the prevalence of comorbidities increased, with $90 \%$ of the participants having at least one comorbidity. The largest increases in prevalence were seen for depression $(+26.9 \%)$, anxiety $(+23.1 \%)$, hypertension $(+21.9 \%)$, osteoarthritis $(+17.1 \%)$, high cholesterol $(+16.3 \%)$, eye diseases $(+11.6 \%)$, osteoporosis $(+10.9 \%)$ and cancer $(+10.3 \%)$. Importantly, 14/19 comorbidities were more common in PwMS than in the general population, with the strongest effect sizes for anaemia, cancer, anxiety, depression, migraine, psoriasis and epilepsy. As these comorbidities contribute to a poorer MS prognosis [30,3], and substantially lower quality of life [31], it is pertinent to try to prevent the development of these comorbidities. This could be achieved by optimising the lifestyle of PwMS where possible and evaluating drug choices that may put them at an additional risk of comorbidities. Further, clinicians may consider assessing comorbidity risk factors and screen for new comorbidities throughout the disease course. Also, optimal management of MS and comorbidities that focuses on an improvement or maintenance of daily function and quality of 
Changes in prevalence of comorbidities in people with MS

life is likely to have positive impacts on healthy lifestyle behaviours [30]. In Australia, MS Nurses play an important role in educating PwMS around the management of symptoms and relapses, healthy lifestyle behaviour, and other aspects of overall wellbeing. The MS Brain Health project also contain useful resources for clinicians, MS Nurses and PwMS [32].

There are several explanations for why many comorbidities may be prevalent at MS symptom onset. First, the comorbidity may be a preclinical symptom of MS. For instance, the high prevalence of depression and anxiety at MS symptom onset has been previously observed in PwMS, suggesting that these symptoms could be among the first clinical signs of MS resulted from immunological and inflammatory changes in the brain [33]. Second, a comorbidity and MS may have overlapping pathogeneses. For example, migraine could be contributing to MS by changing cytokine expressions or increasing blood brain barrier permeability thereby predisposing the individual to having an autoimmune reaction and potentially accelerating demyelination in the central nervous system [34]. Last, a comorbidity and MS may share some of the same risk factors. For example, anaemia and MS are both common in young adult women [35], and the prevalence of psoriasis has been shown to be higher with increasing distance from the equator, potentially indicating that low ultraviolet radiation exposure may be a shared risk factor [36].

With the prevalence of most comorbidities substantially higher at the time of study and the prevalence for many significantly higher than the general population, the accumulation of comorbidities seems to be beyond normal aging. There may be several reasons for this. First, having MS changes lifestyle behaviours. For example, the physical activity levels of PwMS are on average one standard deviation lower than the general population [37], which may contribute to an increased risk in dyslipidaemia, vascular comorbidities $[38,39]$ and osteoporosis [40]. Second, the use of DMTs in people with MS may be associated with an 
Changes in prevalence of comorbidities in people with MS

increased risk of developing or worsening of existing comorbidities. For example, fingolimod is contraindicated for PwMS who had recent cardiovascular problems such as hypertension and hypercholesterolemia [41], while others reported hypertension after natalizumab infusions [42]. Likewise, hypertension is reported in $10 \%$ and $4.3 \%$ of PwMS treated with glatiramer acetate and teriflunomide, respectively [42]. Further, interferons are associated with developing depression [43] and worsening of headache in more than $50 \%$ of people with MS with pre-existing headache [44]. It is also important to note that in most cases and as part of clinical practice, the development or worsening of these comorbidities usually result in a change in DMT to mitigate the risk and the long-term effects of these DMTs on comorbidity burden. Last, MS and comorbidities may have shared risk factors or pathologies that put PwMS at higher risk of accumulating comorbidities. For example, the association between MS and cancer, epilepsy, stomach or thyroid disorders is thought to be a reflection of common genetic, disease or environmental risk factors $[13,45]$.

We did not identify any differences by MS onset-type. We and others have previously shown that people with progressive-onset MS are worse off in terms of patient-reported clinical outcomes [46] and disability progression [47] compared to people with relapse-onset MS. However, our data do not show that people with progressive-onset MS have a higher prevalence at onset or time of study compared to those with relapsing-onset MS, or that the prevalence ratio of comorbidities compared to the general population differed by MS onset type. We were not able to make comparisons for comorbidities that were not sufficiently prevalent in the progressive-onset MS cohort. Despite that, our data seem to suggest that screening and management for comorbidities in PwMS does not need to differ by onset-type.

A key strength of our study is that it is population-based and has been shown to be a representative of the MS population [21]. Despite that, some selection bias may have occurred 
as only half of the invited active AMSLS participants responded to the survey. Those who participated were slightly older, which should not have affected our prevalence ratio estimates since our data were age-adjusted but could have increased the prevalence estimates somewhat. Another strength was that we estimated the prevalence at two important time points using the same MS cohort. We also included a wide range of comorbidities rather than mainly focusing on some comorbidity groups as in the previous studies [48,49]. A limitation is that the comorbidities were self-reported, which may have resulted in recall bias or some misclassification or measurement error, specifically for comorbidities at MS symptom onset. Further, ascertainment bias may have occurred, as some comorbidities may be more or less frequently diagnosed after MS symptom onset because PwMS regularly see a neurologist or other healthcare professionals. This may have been a contributing factor to the high prevalence ratios seen for migraines, epilepsy, depression and anxiety (detection bias) or low prevalence ratios for heart disease, stroke and vascular diseases due to more prevention opportunities after diagnosis (surveillance bias). Also, although we adjusted for age and sex, there may be other confounders such as education, ethnicity, income or treatment methods that were not considered and could have impacted the prevalence ratio estimates. Lastly, given we did not have individual level data of the 2014-15 NHS, we were not able to exclude PwMS in the 201415 NHS. However, it would have only included approximately 20 people with MS out of the 19,259 NHS participants, based on 2017 MS prevalence estimates [50].

Comorbidities are already prevalent in the early stages of MS and having MS may also contribute to accrual of comorbidities. Our findings support the need for optimal screening, prevention of and managing comorbidities from early MS independent of onset type and continuously throughout the disease course as this has the potential to make an impact on the overall MS outcomes. 
Changes in prevalence of comorbidities in people with MS

\section{Acknowledgement}

The authors would like to express their deepest gratitude for all the participants of the Australian Multiple Sclerosis Longitudinal Study for their continuous support and enthusiasm to respond to all surveys.

\section{Compliance with ethical standards}

\section{Funding/Support}

This study was supported by Multiple Sclerosis Research Australia

\section{Conflict of interest/Competing interests}

The authors declare that there is no conflict of interest.

\section{References}

1. Smith AL, Cohen JA, Hua LH (2017) Therapeutic Targets for Multiple Sclerosis: Current Treatment Goals and Future Directions. Neurotherapeutics 14 (4):952-960. doi:10.1007/s13311-017-0548-5

2. Khan F, Turner-Stokes L, Ng L, Kilpatrick T (2007) Multidisciplinary rehabilitation for adults with multiple sclerosis. Cochrane Database Syst Rev 2 (CD006036.):385. doi:https://doi.org/10.1002/14651858.CD006036.pub2

3. Marrie RA, Horwitz RI (2010) Emerging effects of comorbidities on multiple sclerosis. Lancet Neurol 9:820-828. doi:https://doi.org/10.1016/S1474-4422(10)70135-6

4. Marrie RA, Miller A, Sormani MP, Thompson A, Waubant E, Trojano M, O'Connor P, Reingold S, Cohen JA, For the attendees of the International Workshop on Comorbidity in Multiple S (2016) The challenge of comorbidity in clinical trials for multiple sclerosis. Neurology 86 (15):1437-1445. doi:https://doi.org/10.1212/WNL.0000000000002471

5. Marrie RA (2017) Comorbidity in multiple sclerosis: implications for patient care. Nat Rev Neurol 13:375. doi:https://doi.org/10.1038/nrneurol.2017.33

6. Newland PK, Lorenz R, Budhathoki C, Jensen MP (2015) The Presence of Symptoms With Comorbid Conditions in Individuals With Multiple Sclerosis (MS). Clin Nurs Res 25 (5):532-548. doi:https://doi.org/10.1177/1054773815592817

7. Berrigan LI, Fisk JD, Patten SB, Tremlett H, Wolfson C, Warren S, Fiest KM, McKay KA, Marrie RA, For the CIHR Team in the Epidemiology Impact of Comorbidity on Multiple Sclerosis (ECoMS) (2016) Health-related quality of life in multiple sclerosis: Direct and 
Changes in prevalence of comorbidities in people with MS

indirect effects of comorbidity. Neurology 86 (15):1417-1424.

doi:https://doi.org/10.1212/WNL.0000000000002564

8. Salter A, Tyry T, Wang G, Fox RJ, Cutter G, Marrie RA (2016) Examining the joint effect of disability, health behaviors, and comorbidity on mortality in MS. Neurology: Clinical Practice 6 (5):397-408. doi:10.1212/cpj.0000000000000269

9. Marrie RA, Cohen J, Stuve O, Trojano M, Sorensen PS, Reingold S, Cutter G, reider N (2015) A systematic review of the incidence and prevalence of comorbidity in multiple sclerosis: Overview. Mult Scler J 21 (3):263-281.

doi:https://doi.org/10.1177/1352458514564491

10. Marrie RA, Cutter G, Tyry T (2011) Substantial adverse association of visual and vascular comorbidities on visual disability in multiple sclerosis. Mult Scler J 17 (2):14641471. doi:https://doi.org/10.1177/1352458511414041

11. Tettey P, Siejka D, Jr SS, Taylor B, Blizzard L, Ponsonby A-L, Dwyer T, I van der Mei (2016) Frequency of comorbidities and their association with clinical disability and relapse in Multiple Sclerosis. Neuroepidemiology 46:106-113. doi:https://doi.org/10.1159/000442203

12. Marrie RA, Reider N, Cohen J, Stuve O, Trojano M, Cutter G, Reingold S, Sorensen PS (2015) A systematic review of the incidence and prevalence of cardiac, cerebrovascular and peripheral vascular disease in multiple sclerosis. Mult Scler J 21 (3):318-331.

doi:https://doi.org/10.1177/1352458514564485

13. Marrie RA, Horwitz R, Cutter G, Tyry T, Vollmer T (2010) Association between comorbidity and clinical characteristics of MS. Acta Neurol Scand 124 (2):135-141. doi:https://doi.org/10.1111/j.1600-0404.2010.01436.x

14. Ponsonby AL, Dwyer T, van der Mei I, Blizzard L, Taylor B, Kilpatrick T, Simmons R (2006) Asthma onset prior to multiple sclerosis and the contribution of sibling exposure in early life. Clin Exp Immunol 146:463-470. doi:https://doi.org/10.1111/j.1365-

2249.2006.03235.x

15. Marrie RA, Patten SB, Tremlett H, Wolfson C, Warren S, Svenson LW, Jette N, Fisk J, Epidemiology CTit, Impact of Comorbidity on Multiple S (2016) Sex differences in comorbidity at diagnosis of multiple sclerosis: A population-based study. Neurology 86 (14):1279-1286. doi:https://doi.org/10.1212/WNL.0000000000002481

16. Wijnands JMA, Zhu F, Kingwell E, Zhao Y, Ekuma O, Lu X, Evans C, Fisk JD, Marrie RA, Tremlett H (2018) Five years before multiple sclerosis onset: Phenotyping the prodrome. Mult Scler J 25 (8):1092-1101. doi:https://doi.org/10.1177/1352458518783662

17. Roshanisefat H, Bahmanyar S, Hillert J, Olsson T, Montgomery S (2014) Multiple sclerosis clinical course and cardiovascular disease risk - Swedish cohort study. Eur J Neurol 21 (11):1353-e1388. doi:https://doi.org/10.1111/ene.12518

18. Jadidi E, Mohammadi M, Moradi T (2013) High risk of cardiovascular diseases after diagnosis of multiple sclerosis. Mult Scler J 19 (10):1336-1340.

doi:https://doi.org/10.1177/1352458513475833 
19. McKay KA, Kwan V, Duggan T, Tremlett H (2015) Risk factors associated with the onset of relapsing-remitting and primary progressive multiple sclerosis: a systematic review. Biomed Res Int 2015:817238-817238. doi:10.1155/2015/817238

20. Li H, Hu F, Zhang Y, Li K (2019) Comparative efficacy and acceptability of diseasemodifying therapies in patients with relapsing-remitting multiple sclerosis: a systematic review and network meta-analysis. J Neurol. doi:10.1007/s00415-019-09395-w

21. Taylor BV, Palmer A, Simpson Jr S, Lucas R, group NS, Simmons RD, Mason D, Pearson J, Clarke G, Sabel C, Willoughby E, Richardson A, Abernethy D (2013) Assessing possible selection bias in a national voluntary MS longitudinal study in Australia. Mult Scler J 19 (12):1627-1631. doi:https://doi.org/10.1177/1352458513481511

22. Polman CH, Reingold SC, Banwell B, Clanet M, Cohen JA, Filippi M, Fujihara K, Havrdova E, Hutchinson M, Kappos L, Lublin FD, Montalban X, O'Connor P, SandbergWollheim M, Thompson AJ, Waubant E, Weinshenker B, Wolinsky JS (2011) Diagnostic criteria for multiple sclerosis: 2010 revisions to the McDonald criteria. Ann Neurol 69 (2):292-302. doi:https://doi.org/10.1002/ana.22366

23. McDonald WI, Compston A, Edan G, Goodkin D, Hartung H-P, Lublin FD, McFarland HF, Paty DW, Polman CH, Reingold SC, Sandberg-Wollheim M, Sibley W, Thompson A, Noort Svd, Weinshenker BY, Wolinsky JS (2001) Recommended Diagnostic Criteria for Multiple Sclerosis: Guidelines from the International Panel on the Diagnosis of Multiple Sclerosis. Ann Neurol 50 (1):121-127. doi:https://doi.org/10.1002/ana.1032

24. National Health Survey 2014-2015: Users' guide (cat.no. 4364.0.55.001) (2015) www.abs.gov.au. Accessed 20 October 2017

25. Kang JH, Chen YH, Lin HC (2010) Comorbidities amongst patients with multiple sclerosis: a population-based controlled study. Eur J Neurol 17 (9):1215-1219. doi:https://doi.org/10.1111/j.1468-1331.2010.02971.x

26. Marrie R, Horwitz R, Cutter G, Tyry T, Campagnolo D, Vollmer T (2008) Comorbidity, socioeconomic status and multiple sclerosis. Mult Scler 14:1091-1098.

doi:https://doi.org/10.1177/1352458508092263

27. Marrie RA, Horwitz R, Cutter G, Tyry T, Campagnolo D, Vollmer T (2009) Comorbidity delays diagnosis and increases disability at diagnosis in MS. Neurology 72:117-124.

doi:https://doi.org/10.1212/01.wnl.0000333252.78173.5f

28. National Institute for Health Care Excellence (2016) Multimorbidity: clinical assessment and management. https://www.nice.org.uk/guidance/ng56. Accessed June 222019

29. Marrie RA (2018) Comorbidities in Multiple Sclerosis: A Clinical Resource Guide. The Consortium of Multiple Sclerosis Centers (CMSC); Nurse Practitioner Alternatives (NPA); Catamount Medical Education. https://mscomorbidities.com/. Accessed 17 March 2018

30. Weiland TJ, De Livera AM, Brown CR, Jelinek GA, Aitken Z, Simpson SL, Neate SL, Taylor KL, O'Kearney E, Bevens W, Marck CH (2018) Health Outcomes and Lifestyle in a Sample of People With Multiple Sclerosis (HOLISM): Longitudinal and Validation Cohorts. Front Neurol 9 (1074). doi:https://doi.org/10.3389/fneur.2018.01074 
31. Marrie RA, Horwitz R, Cutter G, Tyry T (2012) Cumulative impact of comorbidity on quality of life in MS. Acta Neurol Scand 125 (3):180-186. doi:https://doi.org/10.1111/j.1600$\underline{0404.2011 .01526 . \mathrm{x}}$

32. MS Brain Health (2019) Brain health: time matters in multiple sclerosis. Oxford Health Policy Forum CIC. http://www.msbrainhealth.org/. Accessed 22 January 2019

33. Marrie RA, Reingold S, Cohen J, Stuve O, Trojano M, Sorensen PS, Cutter G, Reider N (2015) The incidence and prevalence of psychiatric disorders in multiple sclerosis: A systematic review. Mult Scler J 21 (3):305-317. doi:https://doi.org/10.1177/1352458514564487

34. Ilya K, Kassandra LM, Joseph H, Alberto A (2011) Increased risk of multiple sclerosis among women with migraine in the Nurses' Health Study II. Mult Scler J 18 (1):90-97. doi:https://doi.org/10.1177/1352458511416487

35. Koudriavtseva T, Renna R, Mandoj C, Piattella MC, Plantone D, Giannarelli D (2015) Association between Anemia and Multiple Sclerosis. Eur Neurol 73 (3-4):233-237. doi:https://doi.org/10.1159/000381212

36. Marrie RA, Patten SB, Tremlett H, Wolfson C, Leung S, Fisk JD (2017) Increased incidence and prevalence of psoriasis in multiple sclerosis. Mult Scler Relat Disord 13:81-86. doi:https://doi.org/10.1016/j.msard.2017.02.012

37. Motl RW, McAuley E, Snook EM (2005) Physical activity and multiple sclerosis: a metaanalysis. Mult Scler J 11 (4):459-463. doi:https://doi.org/10.1191/1352458505ms1188oa

38. Motl RW, Fernhall B, McAuley E, Cutter G (2011) Physical activity and self-reported cardiovascular comorbidities in persons with multiple sclerosis: evidence from a crosssectional analysis. Neuroepidemiology 36:183-191. doi:https://doi.org/10.1159/000327749

39. Palladino R, Marrie RA, Majeed A, Chataway J (2020) Evaluating the Risk of Macrovascular Events and Mortality Among People With Multiple Sclerosis in England. JAMA Neurol 77 (7):1-9. doi:10.1001/jamaneurol.2020.0664

40. Gupta S, Ahsan I, Mahfooz N, Abdelhamid N, Ramanathan M, Weinstock-Guttman B (2014) Osteoporosis and multiple sclerosis: risk factors, pathophysiology and therapeutic interventions. CNS Drugs 28 (8):731-742. doi:https://doi.org/10.1007/s40263-014-0173-3

41. Pelletier D, Hafler DA (2012) Fingolimod for Multiple Sclerosis. N Engl J Med 366 (4):339-347. doi:10.1056/NEJMct1101691

42. Baghbanian SM (2016) Follow-up of hypertension in patients with multiple sclerosis. Iran J Neurol 15 (3):180-181

43. Chiu WC, Su YP, Su KP, Chen PC (2017) Recurrence of depressive disorders after interferon-induced depression. Transl Psychiatry 7 (2):e1026-e1026. doi:10.1038/tp.2016.274

44. Patti F, Nicoletti A, Pappalardo A, Castiglione A, Fermo SL, Messina S, D’Amico E, Cimino V, Zappia M (2012) Frequency and severity of headache is worsened by Interferon- $\beta$ therapy in patients with multiple sclerosis. Acta Neurologica Scandinavica 125 (2):91-95. doi:10.1111/j.1600-0404.2011.01532.x 
45. Marrie RA, Reider N, Cohen J, Stuve O, Trojano M, Cutter G, Reingold S, Sorensen PS (2014) The incidence and prevalence of comorbid gastrointestinal, musculoskeletal, ocular, pulmonary, and renal disorders in multiple sclerosis: A systematic review. Mult Scler J 21 (3):332-341. doi:https://doi.org/10.1177/1352458514564488

46. Zhang Y, Taylor BV, Simpson Jr S, Blizzard L, van der Mei I (2019) Patient-reported outcomes are worse for progressive-onset multiple sclerosis than relapse-onset multiple sclerosis, particularly early in the disease process. Eur J Neurol 26 (1):155-161. doi:https://doi.org/10.1111/ene.13786

47. Salter A, Thomas NP, Tyry T, Cutter GR, Marrie RA (2017) A contemporary profile of primary progressive multiple sclerosis participants from the NARCOMS Registry. Mult Scler J 24 (7):951-962. doi:https://doi.org/10.1177/1352458517711274

48. Marrie RA, Fisk JD, Tremlett H, Wolfson C, Warren S, Tennakoon A, Leung S, Patten SB, On behalf of the CTitE, Impact of Comorbidity on Multiple S (2015) Differences in the burden of psychiatric comorbidity in MS vs the general population. Neurology 85 (22):19721979. doi:10.1212/WNL.0000000000002174

49. Marrie RA, Yu BN, Leung S, Elliott L, Caetano P, Warren S, Wolfson C, Patten SB, Svenson LW, Tremlett H, Fisk J, Blanchard JF (2012) Rising prevalence of vascular comorbidities in multiple sclerosis: validation of administrative definitions for diabetes, hypertension, and hyperlipidemia. Mult Scler J 18 (9):1310-1319.

doi: $10.1177 / 1352458512437814$

50. Campbell JA, Simpson S, Ahmad H, Taylor BV, van der Mei I, Palmer AJ (2019) Change in multiple sclerosis prevalence over time in Australia 2010-2017 utilising disease-modifying therapy prescription data. Mult Scler J:1-14. doi:https://doi.org/10.1177/1352458519861270 
Table 1. Characteristics of people with Multiple Sclerosis (MS) and the Australian population ${ }^{\mathrm{a}}$

\begin{tabular}{|c|c|c|c|c|}
\hline \multirow{2}{*}{ Characteristics } & \multirow{2}{*}{$\begin{array}{c}\text { Total study } \\
\text { sample }\end{array}$} & \multicolumn{2}{|c|}{$\begin{array}{l}\text { MS onset-type of study } \\
\text { sample }^{\text {b }}\end{array}$} & \multirow{2}{*}{$\begin{array}{l}\text { Australian } \\
\text { population }\end{array}$} \\
\hline & & $\begin{array}{l}\text { Relapse- } \\
\text { onset MS }\end{array}$ & $\begin{array}{l}\text { Progressive- } \\
\text { onset } \mathrm{MS}^{\mathrm{d}}\end{array}$ & \\
\hline Total, n (\%) & 1,518 & $1,113(88.1)$ & $150(11.9)$ & $17,733,300$ \\
\hline \multicolumn{5}{|l|}{ Sex, n (\%) } \\
\hline Male & $309(20.4)$ & $190(17.1)$ & $64(42.7)$ & $8,724,300(49.2)$ \\
\hline Female & $1204(79.6)$ & $919(82.9)$ & $86(57.3)$ & $9,006,600(50.8)$ \\
\hline $\begin{array}{l}\text { Currently on disease modifying therapy, } \mathrm{n} \\
(\%)\end{array}$ & $759(62.4)$ & $637(67.7)$ & $35(28.9)$ & - \\
\hline $\begin{array}{l}\text { Age at symptom onset (years), } \\
\text { mean (SD) }\end{array}$ & $36.0(10.8)$ & $35.9(10.4)$ & $40.3(11.4)$ & - \\
\hline $\begin{array}{l}\text { Years since MS symptom onset, } \\
\text { mean (SD) }\end{array}$ & $20.5(10.9)$ & $20.1(10.6)$ & $22.3(11.4)$ & - \\
\hline Age at the time of study, mean (SD) & $55.7(11.2)$ & $55.0(11.2)$ & $62.3(9.3)$ & - \\
\hline \multicolumn{5}{|l|}{ Age groups at the time of study (years), $n(\%)$} \\
\hline$<35$ & $48(3.2)$ & $38(3.5)$ & $0(0.0)$ & $5,553,600(31.3)$ \\
\hline $35-44$ & $226(15.1)$ & $183(16.6)$ & $5(3.4)$ & $3,167,100(17.9)$ \\
\hline $45-54$ & $374(25.0)$ & $276(25.1)$ & $29(19.7)$ & $3,056,500(17.2)$ \\
\hline $55-64$ & 507 (33.8) & 379 (34.4) & $45(30.6)$ & $2,669,600(15.1)$ \\
\hline $65-74$ & $300(20.0)$ & $199(18.1)$ & $58(39.5)$ & $1,937,700(10.9)$ \\
\hline$\geq 75$ & $44(3.0)$ & $26(2.4)$ & $10(6.8)$ & $1,348,800(7.6)$ \\
\hline \multicolumn{5}{|l|}{ Education attainment, n (\%) } \\
\hline Secondary school or less & $356(29.3)$ & $239(25.3)$ & $55(45.5)$ & $6,232,000(35.6)$ \\
\hline Occupational certificate/diploma & $415(34.2)$ & $336(35.6)$ & $36(29.8)$ & $6,431,300(36.7)$ \\
\hline University degree and higher & $443(36.5)$ & $370(39.2)$ & $30(24.8)$ & $4,840,300(27.7)$ \\
\hline \multicolumn{5}{|c|}{ Number of comorbidities at MS symptom onset, $\mathrm{n}(\%)$} \\
\hline 0 & $538(34.8)$ & $365(33.8)$ & $60(40.0)$ & - \\
\hline 1 & $431(28.4)$ & $338(30.4)$ & $29(19.3)$ & - \\
\hline$\geq 2$ & $559(36.9)$ & $410(36.8)$ & $61(40.7)$ & - \\
\hline \multicolumn{5}{|c|}{ Number of comorbidities at the time of study, $\mathrm{n}(\%)$} \\
\hline 0 & $151(10.0)$ & $108(9.7)$ & $12(8.0)$ & - \\
\hline 1 & $198(13.0)$ & $150(13.5)$ & $15(10.0)$ & - \\
\hline$\geq 2$ & $1169(77.0)$ & $855(76.8)$ & $123(82.0)$ & - \\
\hline
\end{tabular}

${ }^{a}$ Based on National Health Survey 2014-15 of the Australian Bureau of Statistics ( $\geq 18$ years old); ${ }^{b}$ Excluded those who ticked "unsure" ( $\left.n=68\right)$ and those who did not specify their MS onset type $(n=187)$; ${ }^{\circ}$ Includes relapsing remitting multiple sclerosis and secondary progressive multiple sclerosis; ${ }^{\mathrm{d}}$ Includes primary progressive multiple sclerosis and progressive relapsing multiple sclerosis. 
Table 2. Prevalence of comorbidities of people with MS between symptom onset and at the time of study

\begin{tabular}{|c|c|c|c|c|c|}
\hline \multirow[b]{2}{*}{ Comorbidity } & \multicolumn{2}{|c|}{ At symptom onset } & \multicolumn{2}{|c|}{ At the time of study } & \multirow{2}{*}{$\begin{array}{c}\text { Absolute } \\
\text { change } \\
(\%)^{a}\end{array}$} \\
\hline & $\begin{array}{l}\text { Total } \\
\text { cases }\end{array}$ & $\begin{array}{c}\text { Prevalence } \\
(\%)\end{array}$ & $\begin{array}{l}\text { Total } \\
\text { cases }\end{array}$ & $\begin{array}{c}\text { Prevalence } \\
(\%)\end{array}$ & \\
\hline Depression & 240 & 15.8 & 648 & 42.7 & 26.9 \\
\hline Anxiety & 242 & 15.9 & 592 & 39.0 & 23.1 \\
\hline Allergies & 443 & 29.2 & 568 & 37.4 & 8.2 \\
\hline Hypertension & 126 & 8.3 & 458 & 30.2 & 21.9 \\
\hline Migraine & 307 & 20.2 & 426 & 28.1 & 7.8 \\
\hline High cholesterol & 109 & 7.2 & 357 & 23.5 & 16.3 \\
\hline Osteoarthritis & 93 & 6.1 & 353 & 23.3 & 17.1 \\
\hline Eye diseases & 41 & 2.7 & 217 & 14.3 & 11.6 \\
\hline Cancer & 55 & 3.6 & 211 & 13.9 & 10.3 \\
\hline Anaemia & 110 & 7.2 & 202 & 13.3 & 6.1 \\
\hline Osteoporosis & 26 & 1.7 & 192 & 12.6 & 10.9 \\
\hline Psoriasis & 80 & 5.3 & 137 & 9.0 & 3.8 \\
\hline Hypothyroidism & 51 & 3.4 & 120 & 7.9 & 4.5 \\
\hline Heart troubles ${ }^{b}$ & 26 & 1.7 & 105 & 6.9 & 5.2 \\
\hline Type 2 diabetes & 7 & 0.5 & 74 & 4.9 & 4.4 \\
\hline Other autoimmune disorders & 28 & 1.8 & 68 & 4.5 & 2.6 \\
\hline Hyperthyroidism & 16 & 1.1 & 45 & 3.0 & 1.9 \\
\hline Rheumatoid arthritis & 13 & 0.9 & 44 & 2.9 & 2.0 \\
\hline Inflammatory bowel disease & 18 & 1.2 & 39 & 2.6 & 1.4 \\
\hline Peripheral vascular disease & 10 & 0.7 & 35 & 2.3 & 1.6 \\
\hline Stroke & 6 & 0.4 & 34 & 2.2 & 1.8 \\
\hline Myocardial infarction & 4 & 0.3 & 30 & 2.0 & 1.7 \\
\hline Epilepsy & 12 & 0.8 & 26 & 1.7 & 0.9 \\
\hline Coeliac disease & 7 & 0.5 & 22 & 1.4 & 1.0 \\
\hline Chronic renal disease & 4 & 0.3 & 20 & 1.3 & 1.1 \\
\hline Bipolar disorder & 9 & 0.6 & 19 & 1.3 & 0.7 \\
\hline Systemic lupus erythematosus & 5 & 0.3 & 16 & 1.1 & 0.7 \\
\hline Type 1 diabetes & 11 & 0.7 & 15 & 1.0 & 0.3 \\
\hline Schizophrenia & 3 & 0.2 & 4 & 0.3 & 0.1 \\
\hline Parkinson's disease & 1 & 0.1 & 2 & 0.1 & 0.1 \\
\hline
\end{tabular}

${ }^{\mathrm{a}}$ Absolute change $(\%)=$ prevalence at the time of study minus prevalence at symptom onset; ${ }^{\mathrm{b}}$ Heart troubles include angina, congestive heart failure and coronary artery disease. Values in bold font indicate $\geq 5 \%$ absolute change. 
Changes in prevalence of comorbidities in people with MS

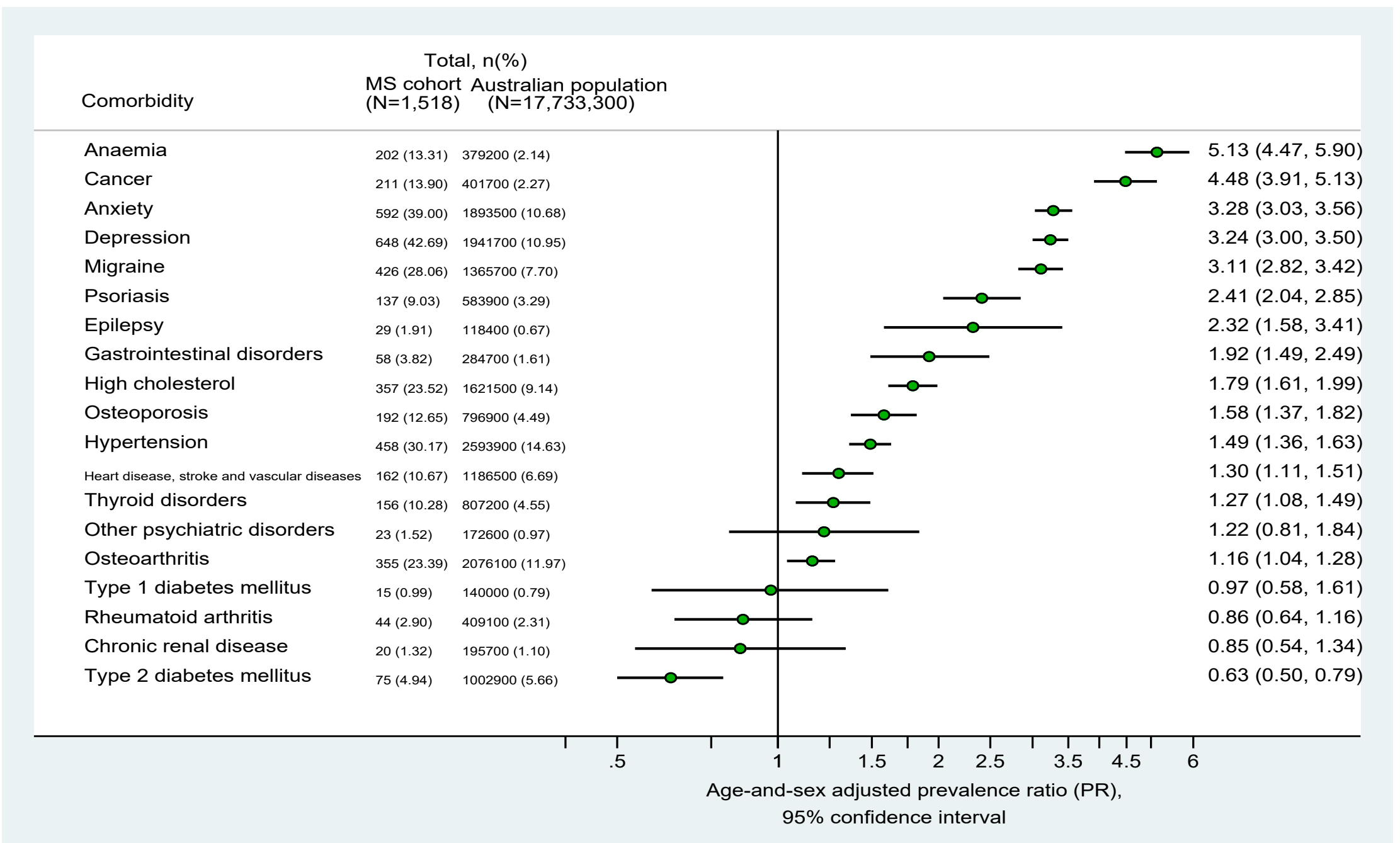

Figure 1. Age-and-sex adjusted prevalence ratios of comorbidities of people with MS compared to the general Australian population ${ }^{\mathrm{a}}$ at the time of study

${ }^{a}$ Based on National Health Survey 2014-15 of the Australian Bureau of Statistics ( $\geq 18$ years old) Gastrointestinal disorders include inflammatory bowel disease and coeliac disease.

Heart disease, stroke and vascular disease include heart trouble (angina, congestive heart failure, coronary artery disease), myocardial infarction, stroke, cerebrovascular disease and peripheral vascular diseases. Thyroid disorders include hypothyroidism, hyperthyroidism and other thyroid disorders.

Other psychiatric disorders include bipolar disease, schizophrenia except depression and anxiety. 
Changes in prevalence of comorbidities in people with MS

Table 3. Prevalence of comorbidities in people with relapse-onset MS compared to progressive-onset MS, with prevalence ratios calculated for comorbidities with $>10$ people.

At MS symptom onset

\begin{tabular}{|c|c|c|c|}
\hline \multicolumn{2}{|c|}{ Total, n (\%) } & \multicolumn{2}{|l|}{$\mathrm{PR}^{\mathbf{b}}(95 \% \mathrm{CI})$} \\
\hline $\begin{array}{c}\text { Relapse- } \\
\text { onset } \\
(\mathrm{n}=1,029)\end{array}$ & $\begin{array}{c}\text { Progressive } \\
\text {-onset } \\
(\mathrm{n}=134)\end{array}$ & Crude & $\begin{array}{l}\text { Age and sex } \\
\text { adjusted }\end{array}$ \\
\hline $170(16.5)$ & $22(16.4)$ & $0.99(0.64-1.55)$ & $0.99(0.61-1.62)$ \\
\hline $177(17.2)$ & $25(18.7)$ & $1.08(0.71-1.65)$ & $0.88(0.55-1.39)$ \\
\hline 349 (33.9) & $34(25.4)$ & $0.75(0.53-1.06)$ & $1.32(0.91-1.93)$ \\
\hline $94(9.1)$ & $13(9.7)$ & $1.06(0.59-1.90)$ & $0.65(0.39-1.10)$ \\
\hline $227(22.1)$ & $25(18.7)$ & $0.85(0.56-1.30)$ & $1.11(0.70-1.76)$ \\
\hline $77(7.5)$ & $14(10.5)$ & $1.40(0.79-2.47)$ & $1.36(0.68-2.72)$ \\
\hline $66(6.4)$ & $13(9.7)$ & $1.51(0.83-2.74)$ & $0.95(0.48-1.87)$ \\
\hline $26(2.5)$ & $8(6.0)$ & - & - \\
\hline $38(3.7)$ & $7(5.2)$ & - & - \\
\hline $82(8.0)$ & $8(6.0)$ & - & - \\
\hline $17(1.7)$ & $4(3.0)$ & - & - \\
\hline $64(6.2)$ & $7(5.2)$ & - & - \\
\hline $39(3.8)$ & $5(3.7)$ & - & - \\
\hline $19(1.9)$ & $5(3.7)$ & - & - \\
\hline $4(1.1)$ & $3(2.2)$ & - & - \\
\hline $19(1.9)$ & $2(1.5)$ & - & - \\
\hline $11(1.1)$ & $2(1.5)$ & - & - \\
\hline $10(1.0)$ & $2(1.5)$ & - & - \\
\hline
\end{tabular}

At the time of study

\begin{tabular}{cc} 
Total, n (\%) & \\
\hline $\begin{array}{c}\text { Relapse- } \\
\text { onset } \\
(\mathrm{n}=1,101)\end{array}$ & $\begin{array}{c}\text { Progressive } \\
\text {-onset } \\
(\mathrm{n}=147)\end{array}$ \\
\hline $469(42.6)$ & $58(39.5)$ \\
$419(38.1)$ & $60(40.1)$ \\
$445(40.4)$ & $39(26.5)$ \\
$338(30.7)$ & $47(32.0)$ \\
$322(29.3)$ & $30(20.4)$ \\
$254(23.1)$ & $47(32.0)$ \\
$258(23.4)$ & $39(26.5)$ \\
$154(14.0)$ & $33(22.5)$ \\
$151(13.7)$ & $24(16.3)$ \\
$151(13.7)$ & $14(9.5)$ \\
$129(11.7)$ & $26(17.7)$ \\
$103(9.4)$ & $13(8.8)$ \\
$91(8.3)$ & $9(6.1)$ \\
$73(6.6)$ & $17(11.6)$ \\
$52(4.7)$ & $9(6.1)$ \\
$53(4.8)$ & $4(3.0)$ \\
$32(2.9)$ & $4(3.0)$ \\
$30(2.7)$ & $7(4.8)$
\end{tabular}

$\mathrm{PR}^{\mathbf{b}}(95 \% \mathrm{CI})$

\begin{tabular}{cc}
\hline Crude & $\begin{array}{c}\text { Age and sex } \\
\text { adjusted }\end{array}$ \\
\hline $0.93(0.71-1.22)$ & $0.97(0.73-1.29)$ \\
$1.07(0.82-1.41)$ & $0.82(0.62-1.09)$ \\
$\mathbf{0 . 6 6}(\mathbf{0 . 4 7 - 0 . 9 1 )}$ & $\mathbf{1 . 5 1}(\mathbf{1 . 0 7 - 2 . 1 4})$ \\
$1.04(0.77-1.41)$ & $1.20(0.87-1.65)$ \\
$1.25(0.95-1.64)$ & $1.18(0.80-1.74)$ \\
$\mathbf{1 . 3 9}(\mathbf{1 . 0 2}-\mathbf{1 . 8 9})$ & $0.93(0.67-1.29)$ \\
$1.13(0.81-1.59)$ & $1.04(0.73-1.47)$ \\
$\mathbf{1 . 6 1}(\mathbf{1 . 1 0 - 2 . 3 4 )}$ & $0.91(0.61-1.35)$ \\
$1.19(0.77-1.83)$ & $0.97(0.62-1.53)$ \\
$0.69(0.40-1.20)$ & $1.45(0.81-2.59)$ \\
$\mathbf{1 . 5 1}(\mathbf{1 . 0 1 - 2 . 3 0})$ & $0.84(0.54-1.29)$ \\
$0.95(0.53-1.68)$ & $1.02(0.56-1.86)$ \\
- & - \\
$\mathbf{1 . 7 4}(\mathbf{1 . 0 3 - 2 . 9 6})$ & $0.98(0.56-1.72)$
\end{tabular}

$1.74(\mathbf{1 . 0 3 - 2 . 9 6}) \quad 0.98(0.56-1.72)$ 
Changes in prevalence of comorbidities in people with MS

\begin{tabular}{|c|c|c|c|c|c|c|}
\hline $\begin{array}{l}\text { Inflammatory bowel } \\
\text { disease }\end{array}$ & $13(1.3)$ & $3(2.2)$ & - & - & $34(3.1)$ & $3(2.1)$ \\
\hline $\begin{array}{l}\text { Peripheral vascular } \\
\text { disease }\end{array}$ & $7(0.7)$ & $2(1.5)$ & - & - & $26(2.4)$ & $5(3.4)$ \\
\hline Stroke & $6(0.6)$ & $0(0.0)$ & - & - & $25(2.3)$ & $4(3.0)$ \\
\hline Myocardial infarction & $2(0.2)$ & $2(1.5)$ & - & - & $18(1.6)$ & $7(4.8)$ \\
\hline Epilepsy & $8(0.8)$ & $2(1.5)$ & - & - & $19(1.7)$ & $3(2.0)$ \\
\hline Coeliac disease & $6(0.6)$ & $0(0.0)$ & - & - & $16(1.5)$ & $2(1.4)$ \\
\hline Chronic renal disease & $4(0.4)$ & $0(0.0)$ & - & - & $18(1.6)$ & $1(0.7)$ \\
\hline Bipolar disorder & $3(0.3)$ & $1(0.1)$ & - & - & $12(0.1)$ & $2(1.4)$ \\
\hline $\begin{array}{l}\text { Systemic lupus } \\
\text { erythematosus }\end{array}$ & $5(0.5)$ & $0(0.0)$ & - & - & $14(0.3)$ & $2(1.4)$ \\
\hline Type 1 diabetes & $10(1.0)$ & $1(0.1)$ & - & - & $13(0.2)$ & $1(0.7)$ \\
\hline Schizophrenia & $1(0.1)$ & $1(0.1)$ & - & - & $1(0.1)$ & $2(1.4)$ \\
\hline Parkinson's disease & $0(0.0)$ & $0(0.0)$ & - & - & $1(0.1)$ & $0(0.0)$ \\
\hline
\end{tabular}

Abbreviations: $\mathrm{PR}=$ Prevalence ratio; $95 \% \mathrm{CI}=95 \%$ confidence interval

${ }^{\text {a }}$ Heart troubles include angina, congestive heart failure and coronary artery disease.

${ }^{b}$ Analysis was only performed for comorbidities with at least 10 participant counts.

Values in bold font denote statistical significance at $95 \%$ confidence interval (CI). 
Table 4. Prevalence ratio (PR) of comorbidities based on the onset-types of people with MS compared to the general Australian population ${ }^{\text {a }}$ at the time of study

\begin{tabular}{|c|c|c|c|c|c|}
\hline \multirow[b]{2}{*}{ Comorbidity } & \multicolumn{2}{|c|}{ Relapse-onset MS } & \multicolumn{2}{|c|}{ Progressive-onset MS } & \multirow[b]{2}{*}{$\begin{array}{l}\mathrm{p} \text {-value for } \\
\text { interaction }^{\mathrm{g}}\end{array}$} \\
\hline & Crude PR $(95 \% \mathrm{CI})^{\mathrm{f}}$ & $\begin{array}{c}\text { Age and Sex adjusted } \\
\text { PR } \\
(95 \% \mathrm{CI})^{\mathrm{f}}\end{array}$ & Crude PR $(95 \% \mathrm{CI})^{\mathrm{f}}$ & $\begin{array}{c}\text { Age and Sex adjusted } \\
\text { PR } \\
(95 \% \mathrm{CI})^{\mathrm{f}}\end{array}$ & \\
\hline Anaemia & $6.41(5.47-7.52)$ & $5.06(4.31-5.94)$ & $4.45(2.64-7.52)$ & $5.20(3.02-8.95)$ & 0.08 \\
\hline Cancer & $6.05(5.16-7.10)$ & $4.48(3.81-5.27)$ & $7.21(4.83-10.75)$ & $3.87(2.57-5.83)$ & 0.47 \\
\hline Depression & $3.89(3.55-4.26)$ & $3.15(2.88-3.45)$ & $3.60(2.79-4.66)$ & $3.20(2.47-4.13)$ & 0.72 \\
\hline Anxiety & $3.56(3.24-3.92)$ & $3.13(2.84-3.44)$ & $3.82(2.97-4.92)$ & $3.80(2.95-4.91)$ & 0.47 \\
\hline Migraine & $3.80(3.40-4.24)$ & $3.09(2.77-3.45)$ & $2.65(1.85-3.79)$ & $2.90(2.02-4.18)$ & 0.20 \\
\hline Psoriasis & $2.84(2.34-3.45)$ & $2.45(2.01-2.98)$ & $2.69(1.56-4.63)$ & $2.29(1.33-3.94)$ & 0.88 \\
\hline Epilepsy & $2.58(1.65-4.05)$ & $2.29(1.46-3.58)$ & $3.06(0.98-9.48)$ & $3.04(0.98-9.42)$ & - \\
\hline Gastrointestinal disorders ${ }^{\mathrm{b}}$ & $2.66(2.00-3.54)$ & $2.09(1.57-2.79)$ & $2.12(0.88-5.09)$ & $1.81(0.75-4.34)$ & - \\
\hline High cholesterol & $2.52(2.23-2.85)$ & $1.79(1.58-2.02)$ & $3.50(2.63-4.65)$ & $1.77(1.32-2.36)$ & 0.78 \\
\hline Hypertension & $2.10(1.89-2.33)$ & $1.57(1.41-1.75)$ & $2.19(1.64-2.91)$ & $1.11(0.83-1.48)$ & 0.06 \\
\hline Osteoporosis & $2.61(2.19-3.10)$ & 1.45 (1.21-1.72) & $3.94(2.68-5.78)$ & $1.96(1.34-2.88)$ & 0.80 \\
\hline $\begin{array}{l}\text { Heart disease, stroke and vascular } \\
\text { diseases }^{c}\end{array}$ & $1.59(1.33-1.90)$ & $1.36(1.13-1.63)$ & $2.124(1.47-3.40)$ & $1.17(0.77-1.17)$ & 0.73 \\
\hline Thyroid disorders $^{\mathrm{d}}$ & $2.35(1.97-2.82)$ & $1.28(1.06-1.53)$ & $1.64(0.91-2.97)$ & $1.03(0.57-1.85)$ & 0.13 \\
\hline Osteoarthritis & $2.00(1.77-2.26)$ & $1.17(1.04-1.32)$ & $2.27(1.66-3.10)$ & $1.07(0.78-1.48)$ & 0.22 \\
\hline Type 1 diabetes mellitus & $1.50(0.87-2.58)$ & $1.17(0.68-2.01)$ & $0.86(0.12-6.11)$ & $0.56(0.08-3.97)$ & - \\
\hline Chronic renal disease & $1.48(0.93-2.35)$ & $1.13(0.71-1.80)$ & $0.62(0.09-4.38)$ & $0.36(0.05-2.56)$ & - \\
\hline Other psychiatric disorders $\mathrm{e}$ & $1.21(0.70-2.09)$ & $0.90(0.52-1.55)$ & $2.80(1.05-7.45)$ & $2.61(0.98-6.95)$ & - \\
\hline Rheumatoid arthritis & $1.18(0.83-1.69)$ & $0.79(0.55-1.14)$ & $2.06(0.98-4.33)$ & $1.13(0.54-2.36)$ & - \\
\hline Type 2 diabetes mellitus & $0.84(0.64-1.10)$ & $0.63(0.48-0.83)$ & $1.08(0.56-2.08)$ & $0.56(0.29-1.07)$ & - \\
\hline
\end{tabular}

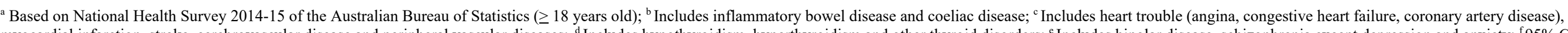

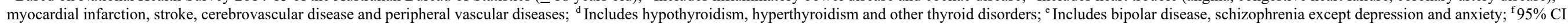

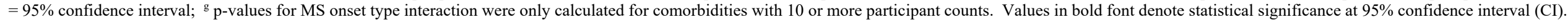

